\title{
Smart cities, urban technocrats, epistemic communities and advocacy coalitions
}

\author{
Rob Kitchin ${ }^{1}$, Claudio Coletta ${ }^{1}$, Leighton Evans ${ }^{2}$, Liam Heaphy $^{1}$ and Darach Mac Donncha ${ }^{1}$
}

1. NIRSA, National University of Ireland Maynooth, County Kildare, Ireland

2. School of Media, University of Brighton, UK.

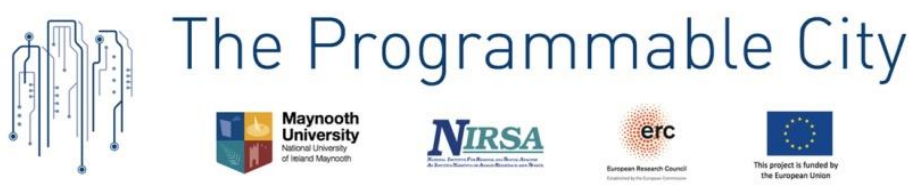

The Programmable City Working Paper 26

http://progcity.maynoothuniversity.ie/

8 March 2017

Prepared for the 'A New Technocracy’ workshop, University of Amsterdam, March 20-21 2017.

Published as an open access pre-print on SocArXiv: https://osf.io/preprints/socarxiv/rxk4r

\begin{abstract}
In this paper, we argue that the ideas, ideals and the rapid proliferation of smart city rhetoric and initiatives globally have been facilitated and promoted by three inter-related communities. A new set of 'urban technocrats' - chief innovation/technology/data officers, project managers, consultants, designers, engineers, change-management civil servants, and academics - many of which have become embedded in city administrations. A smart cities 'epistemic community'; that is, a network of knowledge and policy experts that share a worldview and a common set of normative beliefs, values and practices with respect to addressing urban issues, and work to help decision-makers identify and deploy technological solutions to solve city problems. A wider 'advocacy coalition' of smart city stakeholders and vested interests who collaborate to promote the uptake and embedding of a smart city approach to urban management and governance. We examine the roles of new urban technocrats and the multiscale formation and operation of a smart cities epistemic community and advocacy coalitions, detailing a number of institutional networks at global, supra-national, national, and local scales. In the final section, we consider the translation of the ideas and practices of the smart city into the policies and work of city administrations. In particular, we consider what might be termed the 'last mile problem' and the reasons why, despite a vast and active set of technocrats and epistemic community and advocacy coalition, smart city initiatives are yet to become fully mainstreamed and the smart city mission successfully realized in cities across the globe. We illustrate this last mile problem through a discussion of plans to introduce smart lighting in Dublin.
\end{abstract}

Key words: smart cities, epistemic community, advocacy coalition, technocrats, urban governance, city administration, smart lighting 


\section{Introduction}

Over the past decade, many cities have adopted policies and rolled out programmes and projects designed to transform them into a 'smart city'. It is clear from the plethora of initiatives underway globally that the idea and ideals of smart cities are quite broadly conceived, with enterprises ranging from those: aimed at changing the nature of urban regulation and governance through the use of data-driven systems that make the city knowable and controllable in new, dynamic, reactive ways; to digital systems that improve the efficiency and effectiveness of city services, increase the economic productivity, competitiveness and innovation of businesses, and drive economic growth and urban development; to ICT-enabled schemes that enhance environmental sustainability and urban resilience; to technology-led approaches that improve quality of life and promotes a citizencentric model of development which fosters social innovation, civic engagement and social justice (Townsend 2013; Kitchin 2014). Critically, in all these cases, digital technologies are front-and-centre as a vital ingredient for addressing the major issues facing city managers, urban citizens, and industry leaders.

Accompanying and facilitating the movement towards the creation of smart cities is the rise of a new set of urban technocrats (e.g., chief innovation/technology/data officers, project managers, consultants, designers, engineers, change-management civil servants, and academics), supported by a range of stakeholders (e.g., private industry, lobby groups, philanthropists, politicians, civic tech bodies), and events (e.g., various smart city expos, workshops, hackathons) and governance arrangements (e.g., smart city advisory boards). Indeed, within a relatively short period of time a dense network of new positions and institutional bodies have been created that, on the one hand conceive and produce smart city technologies and initiatives, and on the other seek to roll-out and embed these enterprises within city institutions and change the policy, organizational, resourcing and regulatory urban landscape. This network interlinks a diverse set of stakeholders from across government, NGOs, industry and academia, who are convinced of the benefits of making cities 'smart', and works at multiple scales from the global to local to spread the 'gospel' of smart city rhetoric and convert city leaders to its mission. Once grounded in a locale, the aim is to translate the mission into action and realisation through the creation of a new urban growth regime, with allied stakeholders working in concert to actualize the smart city.

In this paper, we examine this new set of urban technocrats, their various roles, and the professional networks and apparatus that support them in their work. We argue that collectively these technocrats draw from, work with, and in some cases belong to, a new 
smart city epistemic community - that is, a network of knowledge and policy experts that share a worldview and a common set of normative beliefs, values and practices with respect to an issue and help decision-makers identify and deploy solutions to solve problems (Haas 1992). We then detail how this epistemic community intersects with a wider set of smart city interest groups to form an 'advocacy coalition' (Sabatier and Jenkins-Smith 1993) that works at different scales - globally, supra-national, nationally, locally - to spread its rhetoric and mission, providing a number of examples of smart city communities and coalitions at each scale. In the final section, we consider the translation of the ideas and practices of this advocacy coalition into the policies and work of city administrations. In particular, we consider the reasons why smart city initiatives are yet to become fully mainstreamed and the smart city mission successfully realized in cities across the globe.

\section{The new technocrats}

A decade ago, there were few professionals in any stakeholder group (city administrations, industry, academia) who would prefix their title with the words 'smart city' (e.g., 'smart city coordinator', 'smart city project manager', 'smart city consultant'). Moreover, within city administrations there would have been hardly any CIOs (Chief Information Officer - a senior executive officer responsible for IT, including operations and strategy), CTOs (Chief Technology Officer - a senior executive focused on science and technological developments in an organization, including research and development), or CDOs (Chief Data Officer - an executive position responsible for the governance and use of data across an organization); posts that are presently strongly aligned to the smart city mission in those cities that have appointed them. To be sure, there were a plethora of people employed by city administrations that were charged with using IT to deliver city services and to manage and make sense of city data (e.g., IT staff, GIS officers, control room operators), but their roles were quite specific and did not form part of an overarching strategy to drive city operations and services through ICT. Over the past ten years, the situation has changed in many cities, with city administrations employing new technical, operational and policy staff aligned to a smart city agenda. Such staff include those 'smart city' and 'chief' posts mentioned above, plus data coordinators/managers, data scientists, designers, policy specialists, software engineers, and IT project managers. Many of these new technocrats are recruited from industry or academia, seeking to bring specialist knowledge and skills into an organisation, and act as new 'institutional entrepreneurs' (Wejs 2014), driving internal change in how city administrations work. 
These staff occupy roles in existing departments and units, but also populate new units. For example, in Dublin there is Dublinked, responsible for open data, and Smart Dublin, that coordinates smart city initiatives. Together they form a single operational unit. Interestingly, the unit is co-owned across four local authorities (LAs), with members of staff seconded to the unit, and two staff members from each LA sitting on the steering group, with the unit reporting to the CEOs of the four LAs. In the City of Boston new units include the Citywide Analytics team (who monitor and analyse the performance of all the departments and city services in the organisation), an open data team, and New Urban Mechanics (who create new apps and services for citizens and the organization). Often a specialist smart city unit, due to its crosscutting remit, is located within the Mayor's office. In some cases, the new appointments and units accompany wider structural change within the organization as it re-orientates around new modes of corporate governance, procedures, priorities, and policies. The introduction of a CIO and/or CTO/CDO is often accompanied by internal restructuring of roles, responsibilities and reporting lines, for example. Within these new structures, smart city technocrats often span departmental silos, coordinating technical approaches to service delivery across an organisation (not just IT infrastructure and software) and often extensively liaise and collaborate with, and procure services from, other stakeholders.

Smart city rhetoric and initiatives promote intensive collaborations between public sector bodies and other stakeholders, such as industry, NGOs and academia, and actively build on neoliberal arguments concerning the limitations of public sector competencies, inefficiencies in service delivery, and the need for marketization of state services and infrastructures (Graham and Marvin 2001; Greenfield 2013; Kitchin 2014). Public authorities, it is argued, lack the core skills, knowledges and capacities to address pressing urban issues and maintain critical services and infrastructures, which are becoming more socially and technically complex and require multi-tiered specialist interventions. Instead, they need to draw on the competencies held within industry in particular (such as large global consultancies and the producers of software and hardware solutions) that possess sufficient expertise to guide city administrators and can deliver better city services through publicprivate partnerships, leasing, deregulation and market competition, or outright privatization. In such sentiment, the logic of a reliable, low-cost, universal government provision in the public interest is supplemented or replaced by provision through the market, driven in-part or substantively by private interests (Graham and Marvin 2001; Collier et al., 2016).

In this context, there has been a very large growth in consultancies offering specialist smart city services, employing a raft of new smart city 'experts' that provide advice, research, 
training, and a range of related business services with respect to potential solutions, policy formulation, procurement, tracking outcomes, etc., along with new smart city marketers and sales teams. Similarly, tech companies have sought to engage with city administrations to enter in public-private arrangements, sell new products, work jointly with cities on the testbedding of innovations, and to shift mind-sets about how to tackle particular issues. Likewise, academics have been actively engaging with cities on applied, interdisciplinary research concerning urban issues, often in partnership with industry. Indeed, there is a boom in smart cities and urban science research underway globally, with a number of large new, interdisciplinary research centres being established, often funded through research council and matching industry investment (Batty 2013; Townsend 2015).

To encourage city administrations to engage with stakeholders and their services, companies (e.g., IBM ${ }^{1}$ ), philanthropy (e.g., Bloomberg Philanthropies ${ }^{2}$ ), governmental bodies (e.g., government departments and enterprise agencies ${ }^{3}$ ) and research agencies (EU H2020) have sought to incentivize uptake and collaboration through funding multi-stakeholder smart city projects. Sometimes this funding is only available in return for city administrations opening up the organisation to analysis (e.g., IBM swap 'free' consultancy for gaining indepth knowledge of the organisation) and adopting changes to their practices of governance (e.g., Bloomberg Philanthropies expect city administrations to adopt new performance management practices). These have been joined by a plethora of new, specialist institutional bodies and lobby groups at international (e.g., Smart City Council), regional (e.g., European Innovation Partnership on Smart Cities and Communities) and national scales (e.g., City Catapult in the UK); specialist units within other existing institutional bodies (e.g., World Economic Forum ${ }^{4}$, ICLEI - Local Governments for Sustainability ${ }^{5}$ ); new international standards bodies (e.g., City Protocol) and new units within existing bodies (e.g., British Standards Institute); and a vibrant business of conferencing events and training/educational programmes (e.g., Smart City Expo and World Congress).

\footnotetext{
${ }^{1}$ Through its smarter city challenge, https://www.smartercitieschallenge.org/

2 Bloomberg Philanthropies runs a number of smart city programs including 'What Works Cities', 'Mayors Challenge', and 'Sustainable Cities' https://www.bloomberg.org/\#work

${ }^{3}$ The UK Department of Business, Innovation and Skills has run a program (city demonstrators) where cities are financed to adopt smart city initiatives as a way of showcasing solutions that might then be sold globally see https://www.gov.uk/government/news/new-initiative-to-support-40-billion-smart-cities-in-the-uk.

${ }^{4}$ https://www.weforum.org/projects/future-of-urban-development-services

${ }^{5}$ http://www.iclei.org/activities/agendas/smart-city.html
} 


\section{A new epistemic community and advocacy coalition}

This rapidly growing set of smart city professionals within city administrations, governments (local, national, supranational), NGOs, industry, and academia suggest that a new smart cities epistemic community has been formed over the past decade. In his seminal work, Peter Haas (1992: 2) defined an epistemic community as 'network of professionals with recognised expertise and competence in a particular domain and an authoritative claim to policy relevant knowledge within that domain or issue-area.' Such a community of knowledge-based experts help decision-makers identify and define the problems they face along with possible policy solutions, and also to assess policy outcomes. Haas (1992) details that epistemic communities share a set of knowledge, normative and casual beliefs, and practices, and work in common action to forward a particular vision and policy response. They seek to provide contextual framing, advice and social learning to navigate a complex and uncertain social-economic political landscape (Dunlop 2011), and exercise influence through their claims to insightful and authoritative knowledge that has high utility for decision- and policy-makers who maybe lacking sufficient expertise to make informed choices (Haas 2001). Importantly, Haas (1992) argues that they differ from interest groups or policy networks through their claim to authoritative expertise. That said, in general terms, epistemic communities are not necessarily composed of technical and theoretical knowledge experts: they can also emerge from communities of practice which connect experience and practical knowledge, such as in the case of activist and concerned civic groups operating in the health sector (Akrich 2010); or 'expert amateurs' and communities engaged in 'citizen sensing' and peer-to-peer collaboration (Gabrys 2014; Tironi and Criado 2015).

Through their work and network, an epistemic community seeks to reshape the policy landscape and political agenda, but also to reconfigure how policy is made and implemented, and reorganize the associated institutional and organizational landscape. If successful, the community's ideas and practices become institutionalized over time, continuing to shape how problems and solutions are identified and tackled. The community operates and grows through social learning (teaching others their ideas) and professional networking (through working arrangements, workshops, conferences, etc.). Members of an epistemic community can originate from a number of professional, institutional and academic backgrounds - as well as be transnational in nature, working at scales from the local to the global (Dunlop 2013). Decision- and policy-makers can also be members of the community, helping to formulate and distribute ideas and best practices to other constituents. Those studying epistemic communities seek to understand how likeminded actors coalesce into a coherent 
body, how their ideas and practices develop over time and space, and the resources and mechanisms through which their knowledge and advice are introduced into institutional and political processes (Haas 2001).

Dunlop (2013: 230) notes that 'to identify an epistemic community is to identify a set of actors with the professional and social stature to make authoritative claims on politically pertinent and socially relevant issues of the day.' Given that in general terms smart city professionals claim and are often given authoritative voice, share a set of knowledge, beliefs, practices, and aim to craft a particular vision and policy response to urban issues, it thus seems fair to conclude that they constitute an epistemic community. That said, it is also the case that there is a blurred line between a smart city epistemic community and smart city vested interest groups. The two overlap with respect to how they think urban issues should be addressed through technological solutions, and they work in concert to form an 'advocacy coalition' - that is, a coalition of 'people from a variety of positions (elected and agency officials, interest group leaders, researchers) who share a particular belief system' and 'who show a non-trivial degree of coordinated activity over time' (Sabatier and Jenkins-Smith 1993: 25). However, while theoretically an epistemic community does not have direct pecuniary incentives to seek to shape the policy landscape, being driven by normative beliefs, some elements of advocacy coalitions are also motivated by a desire to provide solutions and generate profit. In the latter case, not only is substantive policy advice (means) and policy proposals (ends) being proffered (usually for a hefty fee), but a pathway to a particular solution usually provided by private enterprise (Dunlop 2013). As such, the kinds of advice given by a tech/consultancy company such as IBM is far from impartial and not simply rooted in authorative knowledge expertise, a particular technical approach, and a belief in the power of technology as the most effective way to run cities and fix urban problems. That said, epistemic communities are also clearly driven by self-interest - to see their ideas implemented and to control a policy domain.

Dunlop (2013) notes that the success of an epistemic community is dependent on penetrating governmental institutions and machinery in two ways. First, by insinuating themselves into key bureaucratic positions. Second, by building consensus and persuading institutional actors and decision-makers to their ideas and logic through social learning. Such social learning can take a number of forms. Dunlop (2013) lists five: (1) learning as instrumental - the passing on in technical rather than political terms new ideas and knowledge; (2) learning as persuasion and socialization - seeking to convince actors to change their views on an issue; (3) learning as calculation - as a pragmatic means to achieve 
a particular end that suits both decision-maker and epistemic community; (4) learning as legitimacy - rather than a decision-maker learning 'what works', they seek legitimacy through the symbolic power of the epistemic community's authority; (5) learning as unreflective - as uncritically accepting the ideas and advice of an epistemic community, usually when the general ideas of the community have already been institutionalized. In the case of smart cities, such social learning might occur through consultancy, professional development training, conferences and workshops, co-option in project bids, and hackathons.

With respect to the smart city, an epistemic community and advocacy coalition is evident at four scales: global, supra-national, national and local.

\section{Global epistemic community and advocacy coalition}

In just a handful of years, a number of sizable global smart city consortia have been formed consisted of aligned actors who share a common vision with regards to how cities should be managed and urban issues addressed. Each consortia makes claims to provide city administrations with authorative, neutral, expert advice, resources, and partnerships that can cut through the complexities of managing cities to provide guidance on how to use digital technologies to solve difficult issues/problems.

For example, the 'Smart City Council' (SCC) is a coalition of partners strongly advocating for the adoption of smart city policy and interventions. The SCC consists of 21 'Lead Partners' (including IBM, Cisco, SAS, Schneider Electric, Deloitte, Oracle; Microsoft), 21 'Associate Partners' (including Intel, Huawei, Siemens, Panasonic), and 70 'Advisors' (including the Institute of Electrical and Electronics Engineers (IEEE), International Finance Corporation (part of the World Bank), International Organization for Standardization (ISO), International Telecommunication Union (ITU), World Bank Urban Advisory Unit, and a number of university research centres). Its states:

'To tap into the transformative power of smart technologies, cities need a trusted, neutral advisor. The Smart Cities Council provides that help.' 6 "Smart Cities Council task forces bring together leading experts who work as trusted advisors with public sector leaders and other stakeholders to raise awareness about the smart technologies

\footnotetext{
${ }^{6} \mathrm{http} / / /$ smartcitiescouncil.com/article/about-us-global
} 
that are improving the livability, workability and sustainability of communities around the globe. ${ }^{7}$ (our emphasis)

To that end, the SCC provide a number of resources, events and task forces designed to promote smart city ideas and create social learning.

Similarly, TM Forum ${ }^{8}$ is a large global member association consisting of over 900 members ranging in size from large multinationals to start-ups and university research groups, and also includes some city units such as Smart Dublin. It has a wide remit, promoting the use of digital business in general across government, but has a significant focus on creating smart cities. To this end, TM Forum runs several short and long-term initiatives designed to help advise and guide city management and promote shared knowledge creation and circulation, including: Smart City Global Forum (a global LinkedIn discussion group); Smart City Projects (collaborative assets being collectively produced, including a framework toolkit, best practice guidelines, maturity assessments, benchmarks and catalogues); Smart City InFocus Events (conferences/workshops); Smart City Innovation Centres (development and testing sites); Smart City Hackathons; and a Smart City Think Tank Group (linking together 10 consultancies to develop new ideas and concepts). ${ }^{9}$

A more focused initiative is the Smart City Expo World Congress (SCEWC), held in Barcelona annually since 2011. It states that it is an 'international summit' that has 'succeeded to become a referential global event to support the development of our cities. This professional, institutional and social meeting point is a leading platform of ideas, networking, experiences and international business deals that gathers together the highest level of stakeholders, in the context of urban development., ${ }^{10}$ In 2016 SCEWC attracted 16,668 visitors, with 420 speakers and 590 exhibitors, from over 600 cities. ${ }^{11}$ In 2013, it held its first regional spinout expo in Colombia. In 2017, regional expo and congresses are to be held Spain, Morocco, Mexico, Japan and Argentina. To aid social learning all the sessions at the main congress are videoed and shared via a YouTube channel. There are several other global organizations competing to help guide cities in how they might become smart cities.

\footnotetext{
${ }^{7}$ http://smartcitiescouncil.com/article/council-task-forces

${ }^{8}$ https://www.tmforum.org/about-tm-forum/

${ }^{9}$ https://www.tmforum.org/smart-city-forum/

${ }^{10}$ http://www.smartcityexpo.com/en/event (our emphasis)

${ }^{11}$ http://www.smartcityexpo.com/en/abroad-overview
} 


\section{Supra-national epistemic community and advocacy coalition}

Working somewhat in parallel with the global networks/coalitions, which are primarily driven by business, are supra-national, governmental-led policy and programmatic initiatives. This is particularly the case in the European Union where a number of institutional networks and high-level programmes have been driving the smart cities agenda through a set of institutional arrangements, funding schemes, networking events, and conferences and workshops. These networks and programmes, and their strategies and mechanisms, are overseen through management boards and scientific advisory boards primarily staffed by a mix of academic and public sector actors that act as an epistemic community.

For example, 'The European Innovation Partnership on Smart Cities and Communities' (EIP-SCC) seeks to bring together 'together cities, industry, SMEs, banks, research and other smart city actors' ${ }^{12}$ in order 'to improve urban life through more sustainable integrated solutions ${ }^{\prime 13}$. The EIP-SCC does this by fostering the 'partnering of public and private actors to co-create a pipeline of projects and share their risks.' By 2015 the EIP-SCC documented 370 commitments (which it defines as measurable and concrete smart city engagements/actions) with 4000 public and private partners from 31 countries. These commitments have received hundreds of millions of euro in investment between them to embed smart city doctrine in city administrations and implement on-the-ground smart city initiatives. In addition, the EIP-SCC organizes six 'Action Clusters': sustainable districts and built environment; sustainable urban mobility; integrated infrastructures and processes; business models, finance and procurement; citizen focus; and integrated planning, policy and regulations. These action clusters:

'all build on synergies to help efficient implementation and replication of commitments/solutions ... Our Action Clusters meet regularly. These meetings provide the opportunity to network and collaborate with leading smart city actors allowing for new perspectives and insights. It's all about scale, acceleration, impact, common solutions, integrated approaches and collaboration. ${ }^{, 14}$ (original emphasis)

\footnotetext{
12 https://eu-smartcities.eu/about

13 http://ec.europa.eu/eip/smartcities/

${ }^{14}$ https://eu-smartcities.eu/about
} 
The EIP-SCC state that being 'part of an Action Cluster offers several opportunities for learning, partnering, efficiency gains and new creation of new business.' 15

Collectively, the Action Clusters form various 'marketplaces' for smart city solutions. Indeed, while the EIP-SCC is driven by a strong commitment to improving the quality of life of urban citizens and producing better and more sustainable places to live, there is also a strong market logic that seeks to increase the 'competitiveness of Europe's industry and innovative SMEs' and to capture a significant portion of the rapidly growing global market for implementing smart city initiatives, which they estimate to be 'worth $€ 1.3$ trillion' ${ }^{16}$. It is perhaps no surprise that the stated ambition of EIP-SCC is to 'overcome market fragmentation and achieve scale in building a market for smart city innovations.' Critically, the EIP-SCC operates a mechanism for sharing and embedding the vision of the smart city epistemic community by: funding new technocrat posts, demonstrating the potential of the smart city vision; and fostering social learning. ${ }^{17}$

There are number of similar inter-related initiatives across the complex web of European bodies that have a focus on cities. These are complemented by a range of funding mechanisms for supporting smart city research, projects, networking, and sharing, that link together academia, city administrations, companies and civil society, such as: H2020; JPIUrban Europe; European Regional Development Fund; Connecting Europe Facility; Cohesion Fund; European Social Fund; Eureka Smart City; and Community-Led Local Development ${ }^{18}$. One such initiative is URBACT, administered by the European Territorial Cooperation programme, which aims to foster sustainable integrated urban development in cities across Europe. 'URBACT's mission is to enable cities to work together and develop integrated solutions to common urban challenges, by networking, learning from one another's experiences, drawing lessons and identifying good practices to improve urban policies. ${ }^{19}$ The main target participants include 'practitioners, city managers, elected representatives and stakeholders from other public agencies, the private sector and civil society ${ }^{20}$. URBACT's

\footnotetext{
15 https://eu-smartcities.eu/sites/all/files/EIP-SCC\%20Brochure.pdf

${ }^{16}$ https://eu-smartcities.eu/sites/all/files/EIP-SCC\%20Brochure.pdf

${ }^{17}$ A related initiative is 'The Smart Cities Information System' (SCIS) that 'brings together project developers, cities, institutions, industry and experts from across Europe to exchange data, experience and know-how and to collaborate on the creation of smart cities and an energy-efficient urban environment.' The SCIS provides details on dozens of smart city projects working across hundreds of city sites. http://smartcitiesinfosystem.eu/

${ }^{18}$ https://eu-smartcities.eu/sites/all/files/documents/Smart\%20Cities\%20Funding\%20Guide\%20-

\%20Executive\%20Summary_0.pdf

${ }^{19}$ http://urbact.eu/urbact-glance

${ }^{20}$ http://urbact.eu/urbact-glance
} 
objectives align strongly with enabling the smart city epistemic community and vested interests to achieve their goal of shaping urban policy and practices. URBACT's desired outcome is to: ensure practioners and decision-makers have access to knowledge and knowhow on all aspects of sustainable urban development; improve the capacity of cities to manage sustainable urban policies; improve the design of urban policies and practices; and improve the implementation of integrated urban strategies and actions. It plans to achieve these objectives by facilitating transnational exchange (enabling policy mobility), capacity building (social learning), and capitalisation and dissemination.

\section{National and local-level epistemic community and advocacy coalition}

While the global and supra-national scales provide a transnational means for the knowledge of epistemic communities and advocacy coalitions to circulate and propagate, it is at the national and local-level that the grounding of their ideas takes place through their embedding in institutional structures, appointment of personnel at different scales of government (e.g., national-level departments and agencies, and regional and local/municipal authorities), and the development of specific policies and deployments.

In the Irish context, there are a number of well-funded interdisciplinary research institutes and centres ${ }^{21}$ that specialise in smart cities research that actively partner with numerous industry collaborators (from multinationals such as IBM, Intel, Huawei, CISCO and Dell to SMEs and startups) and work with Irish cities, including extensive testbedding and trialling. Collectively this constitute a functioning national-level epistemic community. In addition, the recently launched (Dec 2016) 'All Ireland Smart Cities Forum'22 brings together representatives from seven Irish cities, five from the South (Cork, Dublin, Limerick, Galway, Waterford) and two from the North (Belfast and Derry) to share insights, support collaborative research, and work with stakeholders on collective city priorities. It is supported in this role by Maynooth University and draws on a national epistemic community and international expertise to help advise city administrations on key policy issues and pragmatic solutions regarding the development of smart cities. More locally, Smart Dublin and Cork Smart Gateway are LA initiatives that seek to guide smart city projects within LA departments and work with 'smart technology providers, researchers and citizens to solve city

\footnotetext{
${ }^{21}$ Insight (www. ), LERO (www.lero.ie), Connect (www. ), Future Cities (www. ), Programmable City (progcity.maynoothuniversity.ie), Tyndall (www. ) and Nimbus (www.)

22 http://www.smartireland.org [not yet live]
} 
challenges and improve city life. ${ }^{23}$ In the context of Smart Dublin, a shared initiative of the four Dublin authorities, the objectives are to: 'stimulate the economic competitiveness of the Dublin Region, through collaboration between private, public and academic partners; drive public sector efficiencies and improve services; and promote transparency and open government.' Beyond its partnerships with universities and industries, it also has an stakeholder advisory board with circa 40 members. Similarly, the Cork Smart Gateway, a partnership between the two Cork local authorities and two Cork-based research institutes, 'works to identify and deploy smart solutions to seize emerging opportunities, solve regional challenges and enhance the reputation of Cork. ${ }^{24}$ In both cases, Smart Dublin and Smart Cork Gateway act as entry routes for the epistemic community and local advocacy coalition into the wider institutional structures.

\section{Bridging the 'last mile' problem}

As detailed, over the past decade: a set of smart city professionals have been successfully inserted into city administrations; an active and lively smart city epistemic community and advocacy coalition has been formed at different scales; an extensive and diverse apparatus of social learning has been rolled out; and in many cases funding opportunities to support smart city initiatives have been created enabling numerous initiatives to be deployed. However, while smart city policy and programmes are being implemented in many cities, it is clear that, with a couple of exceptions that have unique characteristics ${ }^{25}$, they are fragmented in nature and the smart city vision is only partially embedded within city administrations at present. Consequently, the ideas, policies and technologies of the smart city movement have only gained partial traction in driving how city bureaucracies manage and govern their jurisdictions and approach tackling urban issues. Moreover, they are being greeted with apathy or resistance by some staff. In other words, it seems that promoters and technocrats of the smart city vision are having difficulty 'bridging the last mile' from theory and vision to fully mainstreamed policies and adoption across organizations. Here, we want to consider the

\footnotetext{
${ }^{23} \mathrm{http}: / /$ smartdublin.ie/about/

${ }^{24}$ http://www.corksmartgateway.ie/

${ }^{25}$ The exceptions are cities such as Songdo (South Korea) and Masdar (UAE) which have been built on greenfield sites from scratch in the past decade or so and were explicitly pitched as smart city developments (see Cugurullo 2013; Shwayri 2013; Shin et al. 2015). Both cities are unusual with respect to their development history, being conceived and financed by private interests, and are effectively 'gated-communities' at scale. Most of their governance is also delivered through privatised services. Neither is therefore a typical city which has developed over a much longer period of time within a framework of state-led governance.
} 
reasons for these 'last mile' difficulties in ameliorating the work of epistemic communities and advocacy coalitions.

City administrations are to a large degree like an oil tanker. They are large, complex organizations consisting of many departments, with entrenched structures, ways of working, and established legacy systems that create a high degree of embedded path dependency. They are also full of internal politics, fiefdoms, and competing interests. As such, they are not easy to reorientate with respect to shifting how units and staff think about and undertake their work, especially when they directly challenge the paradigmatic training and ideals of professionals schooled to think and act in certain ways (e.g., planners, engineers, architects, educators, social workers, community development workers). A smart city approach promises to create a more nimble, flexible, data-driven, efficient, horizontal organization, cutting across departmental silos and enabling joined-up responses to urban issues. They thus promise to disrupt the status quo and radically change working conditions, including leading to redundancies.

Smart city ideas and policy thus run into internal inertia and resistance by both managers and workers. In addition, they can run into external critique from academics, NGOs, community groups, and politicians (especially on the Left), who hold different views as to the supposed benefits and underlying ideology of the smart city agenda. Part of the critique of the smart city epistemic community is that while they claim to be able to tackle perceived problems, they have a limited perspective shaped by their disciplinary expertise and lack sufficient grounded domain knowledge of an issue (Cullen 2016; Kitchin 2016), often treating the city as a technical system as opposed to a multifaceted place. The result is a form of technological solutionism in which digital technologies are positioned as the answer to all issues, regardless of context and history. Consequently, there has been a marked pushback against the ideas and ideals of the smart city in recent years, especially concerning the role of citizens, the technocratic nature of governance and its instrumental rationality, and the marketization of public services (Greenfield 2013; Kitchin 2014; Mattern 2014; Datta 2015). While the smart city movement has targeted city administrations with some success, it has had less engagement with local politicians and the public, and has largely ignored alternative academic views other than to counter with a call for citizen-engaged smart cities (which tends to be limited to user-feedback rather than bottom-up ownership and participation).

Fuelling resistance and doubts is a sense that the majority of smart city technology is not yet mature and unsuitable for mainstreaming. Technologies are still being developed and tested. They are like drugs in the clinical trial phase. This is borne-out in the large number of 
pilot projects and what has been termed 'experimental' or 'testbed' urbanism or 'living labs.' Practically all EU-funded smart city projects have this status, being initiatives to scope-out, produce and implement proof-of-concepts, and share knowledge about efforts, rather than being market-ready and proven to work in practice. Moreover, it is fair to say that, as with other epistemic communities and advocacy coalitions (Dunlop 2013), there is some diversity of views within them, as well as a structure and power dynamics as to who is shaping and driving the agenda. As such, while there is a general consensus on the utility of digital technologies for tackling urban issues, there is not universal agreement on the form of technical solution or related factors such as the role of citizens in shaping how issues are tackled (Townsend 2013). In other words, smart city ideas and technology are still very much in development phase and investing in them poses a risk for city administrations charged with providing stability, certainty, and reliability in the delivery of city services.

Fostering scepticism is a lack of trust among many city administrators as to whether a smart city approach will work in practice. Cities have a long history of purchasing technologies that are costly and do not always deliver on their promises. This includes the first wave of smart city products sold to them that bound them into unfavourable contracts and supplied technical solutions that did not deliver on their promises. One consequence is that cities are becoming more savvy with the procurement process to ensure that they do not lose control of a service or associated data/IP and that companies provide the service desired.

An additional concern relates to financing and the amount of perceived value for money spent and the return on investment. Many smart city solutions are expensive to procure and service, yet it is not always clear what the return on investment will be beyond promises that a service will improve or an issue be ameliorated in some way. Moreover, it is clear that the same technology will be cheaper and better-in terms of spec, functionality, performance - in a few years, so it is difficult to know when to make the initial investment. Many cities are currently operating in a condition of austerity, so finances for new investments are constrained. As such, although some technologies could save the city money over the long term, the city still must find the initial investment capital. This is why so much effort is now being expended on new business models for smart city investments. Another issue is competing demands for finance with a limited budget. Many services are statutory obligations and unless the smart city technology can address these critical issues, they will have trouble competing for attention and resources.

Many of these concerns were exemplified in research conducted in 2015 on the possible implementation of smart lighting in Dublin, and on the potential of a Central 
Management Systems (CMS) to give a higher degree of control and flexibility over lighting by converting it into digitally networked infrastructure (Evans and Mac Donnacha 2015). The research focussed on the potential benefits and costs of smart lighting and the potential impact on existing infrastructure and workers. Several barriers were identified including: creating interaction issues with citizens over the control of lighting; limits to the efficacy of CMS; the future role of the lighting team in the local authority following implementation (including retraining or job losses); potential issues with retrofitting lights and the current electrical infrastructure in Dublin; costs with updating the lighting infrastructure to accommodate new services; additional risks incurred from employing complex systems; data processing and analysis issues; and scepticism as to the potential cost savings. For example, with regards to the latter, senior managers questioned the efficacy of smart lighting for realising cost reductions. On the one hand, it was recognized that significant savings in costs and $\mathrm{CO}_{2}$ emissions would be achieved by switching to LED lights without a CMS:

'So it is very easy for a local authority to install an LED now and get maximum effect in terms of energy savings and you will get that from the month you put that in you will start to achieve those savings.' (Utilities representative)

On the other, the initial infrastructure costs for updating the network to accommodate CMS would be so enormous that they would nullify any benefits:

'Listen, there will be savings but they will not be savings over the extra cost that you would have been paying. So if you look at it in real terms, there is probably no saving in public lighting because there has been so little investment in it for a number of years, columns need to be replaced [as well as cabling and ducting], so anything that you are saving on the energy side you will have to put back into investing in new infrastructure' (Senior Civil Servant, Dublin City Council).

The lighting department of Dublin City Council currently manages 45,000 lighting units. The current thinking behind any systems upgrade is to address the statutory obligations of public lighting at the best price for the authority, not to address any 'smart city' solution that might be facilitated through advanced CMS usage: 
'Cost wise, we are after doing the tender now and the replacement for those lamps would be about $€ 250$ each. They are not that expensive, that is a pretty good price. But we would intend to roll those LEDs out with pre-programmed dimming [that is, without the ability to be controlled from a distance]. That is what we do. And that is basically where we stand.' (Senior Lighting Engineer, DCC).

There is also a worry concerning the accumulated risks from implementing CMS and upgrading infrastructure (poles, cabling, etc.):

'Your question about the central management system, I think that is another new innovation and again there is a risk involved in that and I think this has got to be taken into account. So if you have one risk, a certain amount, if you have a second one at the same time, it is the square of the risk, so it is four times the risk for two innovations and nine times for three, a square law rather than a linear one.' (Representative of an environmental agency)

In addition, a smart city advocate inside the organization noted that it was difficult to drive change internally:

'Obviously there is a huge knock-on benefit for industry if we are more proactive in terms of our assets. So that is an ongoing piece because one of the challenges is internally there is a huge resistance to looking at anyone touching any of these assets in a way that can drive new opportunities. So that is a key one because it is fine for me to present internally and say I think we should be doing this. And people are like, who the hell are you? You are just an upshot that has rolled in and you are telling us what to do.' (Smart Dublin worker, DCC)

Instead of a city-wide roll-out, Dublin is continuing to develop small-scale deployments. One example is in the Dublin Docklands, itself considered as a 'smart district' for trialling a number of other new technologies such as a smart grid, e-mobility, and environmental sensors. The roll-out of smart lighting in the Docklands responds both to more prosaic fundamentals such as the fact that local lighting is metered unlike elsewhere, and to the medium to long-term goals of ensuring the area showcases the modern and creative capital city as a desired location for investment and locating employment. Within the smart 
district, lighting is seen as both a key utility infrastructure and as a platform for deploying other smart technologies (such as Wi-Fi, sensor deployments, public communication signs, CCTV). While the potential is there to upscale after test-bedding in the Docklands, the agency of the advocacy coalition in the rest of the city region is less powerful, hindered by political resistance to market intrusion, limited budgets for infrastructure and public sector personnel, and institutional and procedural inertia. Perhaps unsurprisingly, city managers generally prefer to exploit the second-mover advantage - that is, the advantage of knowing the system will work in solving a particular problem and improve city services. For example, if city management is going to upgrade 45,000 lampposts to smart lighting, they want to be confident that the system is going to work well and do what was promised. They do not want a newspaper headline that states, " $€ 15$ Million of Taxpayers' Money Wasted."

In addition, the epistemic communities and advocacy coalitions coalescing around the field of smart cities seem to little appreciate the need for democracy, openness and public consultation in city management: mostly, executive decisions are made outside of democratic process and city managers green-light smart city projects with little political, media or public oversight or feedback. In the case of Dublin, local politicians and the public have been ignored almost entirely in the formulation of Smart Dublin and the development and rollout of smart city initiatives. Indeed, nearly all decisions for selecting and implementing smart city initiatives seem to have bypassed public consultation and political debate. As such, the focus of the epistemic community and advocacy has been exclusively targeted at the city bureaucracy. This is perhaps no surprise given that the city has no mayor and is largely run by the CEOs of the four local authorities.

\section{Conclusion}

We have argued in this paper that over the past decade a sizeable and influential smart city epistemic community and advocacy coalition has developed at multiple scales. In a short space of time a new cadre of smart city technocrats - CIOs, CTOs, CDOs, data scientists, designers, policy specialists, software engineers, and project managers - have been appointed to roles in city administrations, organizational structures have been re-jigged to accommodate them, and a raft of new smart city initiatives have been implemented. These technocrats are working with, and supported by, a panoply of external professionals within institutional bodies, academia and companies, who provide a range of services and enact social learning through consultancy, professional development training, conferences and workshops, cooperation in project work, and hackathons. While there are communities of scholars and 
'expert amateurs' that forward an alternative vision of smart cities, particularly a version that is more citizen-focused, -engaged or -run, the dominant paradigm of smart cities is still rooted in a technocratic formulation, albeit one that now acknowledges the need for citizen participation though very much from a civic paternalist or stewardship perspective (Shelton and Lobato 2016).

Collectively the smart city epistemic community and advocacy coalition is starting to reshape urban policy, how funding is distributed and spent, and how city government works, including aiding its marketisation. However, due to a number of issues - not least of which is the relative immaturity of the policy and technical solutions being offered, along with institutional inertia - smart city ideas and ideals have only become partially embedded in city administrations. In effect, while the smart city movement has captured some of the bureaucratic and political terrain at local, national and supra-national scales (e.g., some mayors, Britain's Department of Business, Innovation and Skills, and various EU bodies) it has a 'last mile' problem in many cities.

The extent of this last mile issue varies between municipalities and cities. For example, in Rio de Janeiro the city's control room draws together 32 agencies and 12 private companies into one shared facility producing strong horizontal collaboration (Luque-Ayala and Marvin 2016). In most other cities, control rooms tend to still be single domain in nature, focusing solely on managing one service (e.g., traffic, telecoms, fire service). In the Boston Metro Area, the City of Boston has embraced the notion of a smart city (though it dislikes the term ${ }^{26}$ ), employing over 40 data and smart city specialists within the organization (including a CIO and CDO), creating new units and structures (such as the Citywide Analytics team and New Urban Mechanics), and adopting new forms of data-driven performance management. However, the other 100 municipalities in the Boston Metro Area have only a handful of new smart city technocrats and relatively few initiatives underway. Similarly, the four Dublin local authorities vary in their investment in new personnel and participation in smart city initiatives. However, beyond Smart Dublin, none have made changes to their organizational structures, and many of the staff involved in Smart Dublin are quite junior and have limited power to enact change. Collectively, the LAs are experimenting with using procurement by challenge, but on single issues such as increasing the modal share of bicycle use rather than wholesale infrastructure concerns.

\footnotetext{
${ }^{26}$ As stated in several of our research interviews with officials.
} 
The challenge then for smart city advocates is to bridge this 'last mile', persuading key decision-makers that the smart city approach to managing cities and tackling urban issues through digital technology solutions will radically improve the lives of citizens and help businesses thrive. For this to occur, they need to continue to further enhance the reputation of the epistemic community, strengthen the advocacy coalition, capture more bureaucratic positions, demonstrate the utility of their proposed approach, win the ideological argument over the marketization of city services, and deliver proven, mature, dependable solutions. For those opposed to the notion of a smart city as presently conceived, the challenge is to either re-orientate the imaginaries and logics of the smart city (Townsend 2013; Kitchin 2016) or to offer an entirely alternative view of how cities should be run and managed and urban issues tackled, one rooted in a different set of politics and ideology (e.g., rights, citizenship, participation). These are the battle lines for the next few years.

The smart city epistemic community and advocacy coalition shows no signs of abating, but rather are continuing to grow as ever more technical and scientific academics (e.g., engineers, computer scientists, data scientists, physicists, mathematicians) and companies turn their attention to urban issues and cities further embrace technological solutions to urban management and governance. Those opposing their ideas and ideals show few signs of becoming less entrenched in their critique and the last mile issues we detail will not dissipate overnight. How this will ultimately play out is difficult to pre-determine, but it is fair to say that the new technocrats are unlikely to be leaving city government any time soon, many ICT solutions already deployed are embedded in city governance (e.g., intelligent transport systems) and unlikely to be decommissioned, and large investment is being ploughed into developing and trialling new technology for deployment across domains (e.g., transport, energy, economy, environment, homes).

\section{Acknowledgements}

The research for this paper was provided by a European Research Council Advanced Investigator Award, 'The Programmable City' (ERC-2012-AdG-323636). The analytical frame was inspired by the PhD defence of Michelle Maher, Sociology, Maynooth University, who employed the notion of epistemic communities to examine the politics of pensions in Ireland. 


\section{References}

Akrich, M. (2009) From communities of practice to epistemic communities: Health mobilizations on the internet, Sociological Research Online 15(2), p. 10. http://www.socresonline.org.uk/15/2/10.html (Last accessed 3 Mar 2017)

Batty, M. (2013b) Urban Informatics and Big Data. London: CASA, University College London. http://www.spatialcomplexity.info/files/2015/07/Urban-Informatics-and-BigData.pdf (last accessed 2 Jan 2017)

Collier, S.J., Mizes, J.C. and von Schnitzler, A. (2016) Public infrastructures / Infrastructural publics. Limn 7, http://limn.it/preface-public-infrastructures-infrastructural-publics/

Cugurullo, F. (2013) How to Build a Sandcastle: An Analysis of the Genesis and Development of Masdar City. Journal of Urban Technology 20(1): 23-37.

Cullen, Michelle (2016) Cities on the path to 'smart': information technology provider interactions with urban governance through smart city projects in Dubuque, Iowa and Portland, Oregon. PhD thesis, The London School of Economics and Political Science (LSE). http://etheses.lse.ac.uk/3392/

Datta, A. (2015) New urban utopias of postcolonial India: 'Entrepreneurial urbanization' in Dholera smart city, Gujarat. Dialogues in Human Geography 5(1): 3-22.

Dunlop, C. (2013) Epistemic communities. In M. Howlett, S. Fritzen, W. Xun, and E. Araral (eds) Routledge Handbook of Public Policy. Routledge, London.

Evans, L. and Mac Donncha, D. (2015) Report on public lighting and smart lighting in Dublin. Programmable City, Maynooth. Unpublished report.

Gabrys, J. (2014). Programming Environments: Environmentality and Citizen Sensing in the Smart City. Environment and Planning D: Society and Space 32 (1): 30-48

Graham, S. and Marvin, S. (2001) Splintering Urbanism: Networked Infrastructures, Technological Mobilities and the Urban Condition (Routledge, London)

Greenfield, A. (2013) Against the Smart City. New York: Do Publications.

Haas, P.M. (1992) 'Introduction: epistemic communities and international policy coordination', International Organization 46(1): 1-35.

Haas, P.M. (2001) 'Policy knowledge: epistemic communities' In N. J. Smelser \& B. Baltes (eds.), International Encyclopedia of the Social and Behavioral Sciences vol 17: 1157811586

Kitchin, R. (2014) The real-time city? Big data and smart urbanism, GeoJournal, 79(1): 1-14.

Kitchin, R. (2016) Reframing, reimagining and remaking smart cities. Programmable City Working Paper 20, https://osf.io/cyjhg/ 
Luque-Ayala, A. and Marvin, S. (2016). The maintenance of urban circulation: an operational logic of infrastructural control. Environment and Planning D: Society and Space 34(2): 191-208.

Mattern, S. (2014) Interfacing urban intelligence. Places: Design Observer http://places.designobserver.com/feature/how-do-we-interface-with-smart-cities/38443/ (last accessed 17 July 2014).

Sabatier, P.A. and Jenkins-Smith, H. (1993) Policy Change and Learning: An Advocacy Coalition Approach. Boulder, CO: Westview Press.

Shelton, T. and Lodato, T. 2016. 'Actually existing smart citizens': expertise and (non)participation in the making of the smart city. Presented at the Creating Smart Cities Workshop. The Programmable City Project, Maynooth University, Ireland, Sept 5-6. http://progcity.maynoothuniversity.ie/2016/10/creating-smart-cities-workshop-videossession-2/

Shin, H., Park, S.H. and Sonn, J.W. (2015) The emergence of a multiscalar growth regime and scalar tension: the politics of urban development in Songdo New City, South Korea. Environment and Planning C 33(6): 1618-1638

Shwayri, S.T. (2013) A model Korean ubiquitous eco-city? The politics of making Songdo. Journal of Urban Technology 20(1): 39-55.

Tironi M. and Criado T.S. (2015) Of sensors and sensitivities. Towards a cosmopolitics of 'Smart Cities'? Tecnoscienza: Italian Journal of Science \& Technology Studies 6(1): 89108.

Townsend, A. (2013) Smart Cities: Big data, civic hackers, and the quest for a new utopia. New York: W.W. Norton \& Co.

Townsend, A. (2015) Making Sense of the New Science of Cities. Rudin Center for Transportation Policy \& Management and Data and Society Research Institute, New York University. http://www.citiesofdata.org/wp-content/uploads/2015/04/Making-Sense-ofthe-New-Science-of-Cities-FINAL-2015.7.7.pdf (last accessed 2 Jan 2017)

Wejs, A. (2014) Integrating climate change into governance at the municipal scale: An institutional perspective on practices in Denmark. Environment and Planning C: Government and Policy 32(6): 1017-1035. 